\title{
Estudos sobre o caroteno em algumas variedades amazônicas de mandioca (Manihot esculenta Crantz)
}

\author{
H. A. Marinho (") \\ D. B. Arkcoll (")
}

\begin{abstract}
Resumo
Foram conduzidos experimentos com raizes de mandioca nos quais foi verificado um efeito da variedade, idade e corte transversal, sobre o conteúdo de caroteno. Notaram-se grandes perdas ocorridas durante o processamento das raizes na farinha d'água consumida na região. Essas perdas podem ser reduzidas se as raízes forem bem fermentadas e a farinha armazenada em boas condições. Constatou-se que dos carotenóides $30 \%$ era Beta caroteno e o consumo de $100 \mathrm{~g}$ de farinha pode fornecer $20 \%$ das recomendações diárias de vitamina $A$.
\end{abstract}

\section{INTRODUÇÃo}

Vários estudos nutricionais da Amazônia têm apontado a hipovitaminose A como um dos problemas principais (Silva, 1959; Lowenstein, 1967; Shrimpton \& Giugliano 1979 e Marinho et al., 1980). No entanto, existem frutas com elevados teores de carotenóides na região (Guimarães \& Pechnik, 1956; Pechnik \& Guimarães, 1957; Aguiar et al., 1980). O consumo destas frutas e hortaliças, infelizmente, é demasiadamente baixo nas classes menos favorecidas que também sofrem de doenças gastrointestinais que reduzem a absorção da vitamina A (Sivakumar \& Reddy, 1975; Borges, 1978).

O principal alimento da dieta é a farinha de mandioca fermentada que varia em cor, do branco ao castanho ou amarelo. Guimarães \& Pechnik (1956), Maravalhas (1964) e Guimarães \& Barros (1971) anotaram que a farinha amarela comum na Região Amazônica tem essa cor face ao seu conteúdo de carotenóides. A farinha amarela é mais cara que a farinha branca e por esse motivo o consumidor de menor poder aquisitivo normalmente não a inclui em sua alimentação.
O programa de melhoramento da mandioca do INPA tem procurado as variedades mais ricas em carotenóides, visando futuramente à produção em abundância de variedades de mandioca amarela conseqüentemente baixando o custo das farinhas de mesma cor. O melhoramento proporcionará sobretudo efeito benéfico no estado nutricional relacionado à vitamina $A$ das populações mais carentes deste nutriente.

O estudo do processo de fazer farinha e localizar onde estão sendo perdidos os carotenóides no processamento, e a maneira de impedir qualquer perda, é também um dos objetivos deste trabalho.

\section{MATERIAL E MÉTODOS}

Processamento da Farinha D'Água - As raízes frescas de mandioca depois de lavadas e descascadas, foram imersas em água de chuva, com inóculo de raízes fermentadas, por 5 dias. Durante a fermentação o pH baixou para 4 , o ácido cianídrico foi liberado e as raízes amoleceram, facilitando o seu ralamento. Passado este período as raizes moles foram raladas, peneiradas e espremidas por processo manual. Obteve-se um líquido amarelo denominado tucupi e uma massa também amarela a qual foi peneirada e torrada dando origem à farinha d'água amarela (Cf. Fluxograma).

Processamento da Farinha Seca $-\mathrm{O}$ processo foi idêntico ao da farinha d'água com exceção da fermentação.

Extração e Dosagem de Carotenóides Dez gramas de cortes transversais de raízes frescas ou de farinha de mandioca, foram maceradas num almofariz com $50 \mathrm{ml}$ de mistura

(*) - Instituto Nacional de Pesquisas da Amazônia, Manaus. 


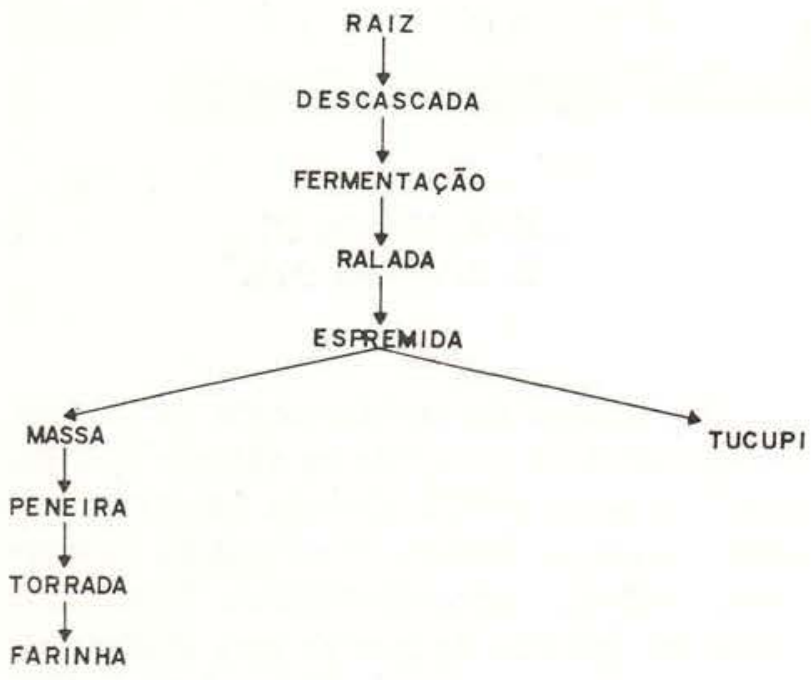

Fluxograma do processo para produção de farinha d'água

de éter de petróleo (faixa de ebulição $60-70^{\circ} \mathrm{C}$ ) com acetona gelada (2:1). A extração foi repetida três vezes com volume de $25 \mathrm{ml}$ cada vez. A solução foi lavada com água destilada num funil de separação protegido com um papel de alumínio para evitar a luz que oxida os carotenos; agitou-se e deixou-se separar as fases, retirou-se a fase aquosa, que se abandonou. Repetiu-se a lavagem da fase etérica com água destilada mais duas vezes. Secou-se a camada de éter de petróleo passando-se a mesma por uma pequena coluna $(1 \times 5 \mathrm{~cm})$ de $\mathrm{Na}_{2} \mathrm{SO}_{4}$ anidro. Coletou-se o extrato e diluiu-se com éter de petróleo com a mesma faixa de ebulição num balão volumétrico.

Dez $\mathrm{ml}$ de tucupi foi extraído de maneira semelhante através de separação inicial das soluções numa centrífuga a $2000 \mathrm{rpm}$ durante 2 minutos. As operações seguintes como lavagem, secagem e diluição, realizou-se de modo idêntico ao acima citado.

As leituras dos extratos diluídos foram realizadas no espectrofotômetro Zeiss mod. P.M. $Q_{3}$ a $436 \mathrm{~nm}$ e as concentrações de caroteno foram calculadas pela fórmula da A.O.A.C., 1975.

A separação e identificação de carotenos foram realizadas através de cromatografia de camada fina de sílica, segundo o método descrito pela A.O.A.C., (1975) com padrões de La Roche.

\section{Resultados E DISCUSSÃo}

O estudo de 40 variedades de mandioca amarela indicou uma variação de 0 a $3,2 \mathrm{mg}$ de caroteno/100 g de raiz e 0 a $2,1 \mathrm{mg}$ para farinha. (Tabela 1). Revela ainda a grande perda que ocorre no processamento, pelo fato de a farinha representar um terço do peso original da raiz.

Observa-se na Tabela 2 que os conteúdos de caroteno variam segundo o corte transversal da raiz. Também foi verificado um aumento de carotenóides em função da idade confirmando as observações de Guimarães \& Barros (1971).

Os cortes transversais apresentam uma distribuição não uniforme da cor amarela sendo no centro um amarelo concentrado e nas periferias um amarelo pálido. O tamanho e as partes da raiz têm pouco efeito (Tabela 2),

Encontram-se na Tabela 3 as perdas médias de caroteno em 20 amostras. Pode notarse que, na farinha fermentada (d'água), a recuperação foi $35 \%$ e para farinha seca apenas $4,6 \%$. As recuperações totais foram somente

TABELA 1 - 0 conteúdo de caroteno" de diversas variedades de mandioca

\begin{tabular}{ll|l|l}
\hline \multirow{3}{*}{ Variedade } & Raiz & Farinha \\
\hline IM & 040 & 0 & 0 \\
096 & 0 & 0 \\
035 & 0.22 & 0.19 \\
139 & 0.49 & 0.45 \\
092 & 1.40 & 1.22 \\
172 & 1.89 & 1.20 \\
103 & 1.93 & 1.59 \\
171 & 3.20 & 2.09 \\
\hline
\end{tabular}

(") - Caroteno expresso em $\mathrm{mg} / 100 \mathrm{~g}$ da raiz ou farinha. 
TABELA 2 - Outras fontes de variação no conteúdo de caroteno*

\begin{tabular}{|c|c|c|c|c|c|c|c|c|c|c|c|c|}
\hline \multirow{2}{*}{\multicolumn{2}{|c|}{ Variedade }} & \multicolumn{3}{|c|}{ Tamanho da Raiz } & \multicolumn{3}{|c|}{ Parte da Raiz } & \multicolumn{3}{|c|}{ Corte Transversal } & \multicolumn{2}{|c|}{ Idade } \\
\hline & & Pequena & Média & Grande & Ápice & Centro & Base & Externa & $\begin{array}{c}\text { Interme- } \\
\text { diária }\end{array}$ & Interna & $\stackrel{14}{ }^{14}$ & $\begin{array}{c}19 \\
\text { Meses }\end{array}$ \\
\hline IM & 175 & 0.15 & 0.28 & 0.28 & & & & & & & & \\
\hline & 104 & 0.18 & 0.18 & 0.18 & & & & & & & & \\
\hline & 139 & 0.42 & 0.44 & 0.45 & & & & & & & & \\
\hline & 085 & & & & 0.68 & 0.70 & 0.86 & & & & & \\
\hline & 103 & & & & & & & 0.96 & 1.99 & 2.15 & & \\
\hline & & & & & & & & 0.42 & 0.73 & 1.19 & & \\
\hline & $68 \mathrm{~A}$ & & & & & & & & & & 0.33 & 0.77 \\
\hline
\end{tabular}

(*) - Caroteno expresso em $\mathrm{mg} / 100 \mathrm{~g}$ da raiz.

TABELA 3 - Caroteno da raiz original recuperado na farinha e no tucupi ${ }^{*}$

\begin{tabular}{l|r|r|c}
\hline \multicolumn{1}{c|}{ Tipo } & Farinha & Tucupi & Total \\
\hline Farinha D'água & 35.2 & 33.2 & 68.4 \\
Farinha Seca & 4.6 & 37.3 & 43.9 \\
\hline
\end{tabular}

(*) - Caroteno expresso em porcentagem de conteúdo da raiz.

$68 \%$ a $44 \%$, evidenciando perda de uma quantidade considerável dos carotenóides no processamento.

A fermentação oferece alguma proteção e a Tabela 4 aponta a importância de permitir-se que as raízes fermentem bem a um $\mathrm{pH}$ abaixo de 4 para que haja boa recuperação de caroteno. Cinqüenta amostras obtidas localmente apresentaram $\mathrm{pH}$ que variou de 3,8 a $4,7 . \mathrm{O} \mathrm{pH}$ ácido parece diminuir as perdas provavelmente causada por oxidação enzimática.

Grande quantidade $(35 \%)$ de caroteno é perdido no tucupi. Parece que o caroteno está ligado a proteína formando um complexo, pois, uma precipitação amarela pode ser obtida no tucupi a um pH 4 contendo $16 \%$ de proteína e a totalidade de pigmento. A considerável quantidade perdida no tucupi pode ser aproveitada consumida em pratos regionais como, pato no tucupi, tacacá, além de ser substituto do vinagre, já que contém ácido acético (em maior proporção), além dos ácidos propiônico, butírico, valérico, succínico, palmitico e oléico (Albuquerque et al., 1978; Silva et al., 1979).

$\mathrm{Na}$ Tabela 5, podem observar-se as perdas por armazenagem extremamente altas à temperatura ambiente $\left(22-35^{\circ} \mathrm{C}\right)$. Isso sugere a necessidade de acrescentar-se antioxidantes, caso a farinha não seja consumida dentro de poucas semanas. As farinhas estudadas eram de textura fina por terem sido produzidas em laboratório. Alguma proteção adicional talvez possa ser obtida nas farinhas de textura grossa encontrada no mercado. A natureza ácida destas farinhas poderia também protegê-las do ataque de fungos e insetos nos trópicos quentes e úmidos. A textura arenosa e pegajosa

TABELA 4-Efeito do tempo de fermentação sobre o pH e concentração de caroteno na farinha

\begin{tabular}{c|c|c}
\hline Tempo/Horas & $\mathrm{pH}$ & $\begin{array}{c}\text { Caroteno } \mathrm{mg} / 100 \mathrm{~g} \\
\text { na Farinha }\end{array}$ \\
\hline 0 & 6.9 & 0.34 \\
24 & 6.2 & 0.35 \\
48 & 4.0 & 0.55 \\
72 & 4.0 & 0.72 \\
96 & 3.9 & 0.81 \\
120 & 3.9 & 0.98 \\
144 & 3.9 & 0.90 \\
\hline
\end{tabular}


TABELA 5 - Concentração de caroteno* em farinha ar. mazenada em diversas condiçôes

\begin{tabular}{|c|c|c|c|}
\hline \multirow{2}{*}{$\begin{array}{l}\text { Tempo } \\
\text { Meses }\end{array}$} & \multicolumn{3}{|c|}{ Armazenamento } \\
\hline & $\begin{array}{c}\text { Congelador } \\
-10^{\circ} \mathrm{C}\end{array}$ & $\begin{array}{c}\text { Ambiente } \\
\text { Lata }\end{array}$ & $\begin{array}{c}\text { Ambiente } \\
\text { Saco Plástico }\end{array}$ \\
\hline 0 & 0.94 & 0.94 & 0.94 \\
\hline 1 & 0.06 & 0.14 & 0.9 \\
\hline 3 & 0.02 & 0.12 & 0.85 \\
\hline 6 & 0.01 & 0.11 & 0.55 \\
\hline
\end{tabular}

(*) - Caroteno expresso em $\mathrm{mg} / 100 \mathrm{~g}$ de farinha.

resultante da degradação microbal do amido para dextrina, no entanto, gruda nos dentes e pode contribuir para a alta incidência de cárie dentária na região.

Todas as variedades que contém caroteno até agora encontradas são mandiocas bravas. Uma macaxeira que se tornou amarela após o cozimento não apresentou caroteno. 0 pigmento é solúvel em água e provavelmente uma leucoantocianina. É muito comum acrescentaremse agentes corantes amarelos às farinhas para obtenção de maior preço. A açafroa (Curcuma doméstica) é comumente utilizada localmente à razão de 1 por 10.000 . O pigmento é curcumina. Outro corante utilizado na Região Amazônica para avivar a cor amarela da farinha é o urucu (Bixa orellana) que tem como pigmento a bixina (Albuquerque, 1969). Em Ghana, emprega-se o óleo de dendê o qual contribui com alto teor de caroteno.

Um estudo mais antigo sugeriu que grande parte de caroteno está sob a forma de alfa caroteno (Maravalhas, 1964). Outros trabalhos mostram predominância absoluta de beta caroteno neste material (Guimarães \& Barros, 1971; Figueiredo et al., 1977). Os nossos estudos mostraram que aproximadamente $30 \%$ era beta caroteno e os restantes eram mono e dehidroxi-caroteno.

Os grupos de especialistas da FAO/OMS, 1965; FAO/OMS, 1975; OMS, 1976; OMS, 1978, adotaram um método de eficiência básica de conversão de carotenóides em alimentos para seres humanos, o qual diz que nos seres humanos o aproveitamento do beta caroteno pre- sente nos vegetais é aproximadamente seis vezes inferior ao correspondente retinol e a atividade dos carotenóides totais (com atividade de vitamina A) são considerados a metade do beta caroteno. Por conseguinte, cem gramas de farinha de boa qualidade contendo $2 \mathrm{mg} / 100 \mathrm{~g}$ de carotenóides totais equivale a $167 \mathrm{mg}$ de retinol os quais poderiam contribuir com aproximadamente $20 \%$ das ingestas recomendadas ( $750 \mathrm{mg}$ de retinol) para um adulto.

Espera-se que estas variedades ricas em pró-vitamina A sejam utilizadas pelos fabricantes de farinha do Amazonas e em outras partes do Brasil e do mundo onde a mandioca branca constitui o alimento básico e a xeroftalmia é comumente encontrada (Oomen, 1961).

\section{AgradecIMENTOS}

- Ao Dr. Roger Shrimpton, Chefe do Departamento de Microbiologia, Alimentação e Nutrição do INPA, pelas sugestões e idéias transmitidas durante a realização do trabalho.

- A Srta. Janete Seixas, Bolsista do INPA, pela colaboração nos trabalhos técnicos.

- A Produtos Roche Químicos e Farmacêuticos S.A. que gentilmente doou padrão de Beta caroteno.

\section{SUMMMARY}

The carotenoid content of cassava roots varies with variety, age and the cross section of the root. Large losses occur during the processing of roots into the fermented flour eaten in the region. These losses can be reduced if the roots are well fermented and the flours are stored in good conditions.

About $30 \%$ of the carotenoides is Beta carotene and the consumption of $100 \mathrm{~g}$ of fiour could provide about $20 \%$ of the daily adult recommended intake for vitamin A.

\section{REFERÊNCIAS BIBLIOGRÁFICAS}

Albuguerque, M.

1969 - A Mandioca na Amazônia. IPEAN, Comunicado Técnico, 142 - Belém. 
Albuquerque, M.; RAMOS, E.M.C.; Gonçalves, W.M.F.; Barriga, J.P.; BARbosa, W.C.; ANDRAdE E SIlVa, D. DE

1978 - Utilização do Tucupi na Coagulação do Látex da Seringueira. IPEAN, Comunicado Técnico, 48. Belém.

Aguiar, J.P.L.; MARINHO, H.A.; REBELO, Y.S.;

SHRIMPTON, R.

1980 - Aspectos Nutritivos de Alguns Frutos da Amazônia. Acta Amazonica, 10 (4):

A.O.A.C.

1975 - Handbook of Chemical Analysis.

BORGES, E.L.

1978 - Efeito do Consumo de Açúcar Fortificado com Vitamina A por Pré Escolar. Tese de Mestrado em Ciências - UFMG. 46 p.

Figueiredo, I.B ; Vitti, P.; Pereira, A S.

1977 - Comportamento de Substâncias Nitrogenadas $\in$ Caroteno em duas Variedades de mandioca. Boletim do ITAL, 51-145-150.

Guimarães, L.R. \& Pechnik, E.

1956 - Contribuição ao Estado dos Alimentos da Região Amazônica. Arq Bras. de Nutrição, 15:1; 15:24 (Janeiro-Junho).

Gutmarães, M.L. \& Barros, M.S.C. nico de Divisão de Tecnologia Agrícola e Alimentos, (4): 1-4.

1971 - Sobre a Ocorrência de Beta caroteno em va. riedades de mandioca amarela. Boletim Téc-

LOWENSTEIN, F.W.

1967 - Report on Nutrition Surveys in Brazilian. Amazon Communities between 1955-1957 Atas do Simpósio sobre Biota Amazônica, 6 (Patologia): 177 e 184.

Maravalhas, N.

1964 - Cinco Estudos sobre a Farinha de Mandioca. Publ, do INPA, (6): 39-40.

MARINHo, H.; SHRIMPton, R.; FrınÇA, T.S.; REbÊLo, Y.S.

s/d - Niveis Sérios de Vitamina A em Operários de Manaus. Acta Amazonica (em preparação).
OOMEN, H.A.P.C.

1961 - A Global Survey on Xerophtalmia: Epidemiology and Public Health Aspects of Hypovitaminosis A. Trop. Geog. Med., 16: 271315.

ORganizacion de LAS NaCIONES UNIDAS PARA LA

Agricultura y LA ALIMENTACION

1965 - Necessidades de Vitamina A, Tiamina, Riboflavina y Niacina Roma p. 17-31.

Organización Mundial de la Salun

1975 - Manual sobre Necessidades Nutricionais de Hombre. p. 30-32.

1976 - Carência de Vitamina A y Xeroftalmia p. 11.

1978 - Guia Prático para la Deteccion, Prevención y Tratamento de la Xeroftalmia. p. 9

Pechnik, E. \& Guimarães L.R.

1957 - Alguns representantes do Reino Vegetal Portadores do Elevado Potencial Pro-Vitamínico A. Arq. Bras. de Nutrição, 13 (1): 1-15, $15 \mathrm{p}$.

Shrimpton, R. \& Giugliano, R.

1979 - Consumo de Alimentos e Alguns Nutrientes em Manaus - 1973.1974. Acta Amazonica, 9 (1): 117-141.

Silva, M.L.; Maia, J.G.; Wolter, W.; Mourão, A.P.

1979 - Determinaçāo de Ácidos Orgânicos em Plantas e Alimentos da Amazônia 1. Ácidos Orgânicos do Tucupi. Acta Amazonica, 6 (2): $235-236$.

Silva, W.

1959 - Inquérito sobre o Consumo de Alimentos e Nutrientes, Avaliação do Estado Nutricional e Situação Econômica da População Amazônica. Bol. Com. Nas. Alim., 4 (2): JulhoSetembro R.J.

SiVAKumar, B. \& REDDY, V.

1975 - Absorption of Vitamin A in Children with ascariasis. J. Trop. Med. Hyg., 78: 114-115 (1975).

(Aceito para publicação em 24/09/80) 